\title{
Medical Education Through Distance Learning: How Does it Work?
}

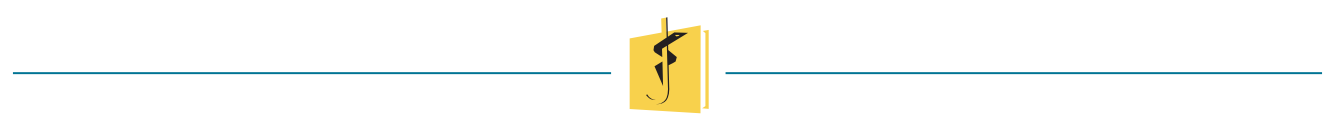

Leilani B. Mercado-Asis, MD, PhD, MPH, MEd (DE) $)^{1,2}$

\begin{abstract}
The application of distance learning in medical education has been a continuous challenge to approximate face-to-face clinical skill teaching. Nonetheless, online education has proven to be effective in addressing student satisfaction, engagement, motivation and excellent academic performance. How elearning evolved in a medical setting through the years and the evolution of state-of-the-art teaching resources will be discussed accordingly.
\end{abstract}

\section{INTRODUCTION}

Distance education (DE) is an institution-based learning characterized by separation of the teacher and student whose interaction and sharing of learning experiences is made possible with the use of technology.[1] DE is termed interchangeably with elearning or online learning. The adaption of $D E$ in medical education has long been proven to be advantageous with regard to students' adaptability, satisfaction, engagement, motivation, and improvement of performance. These medical students' positive attributes developed with the rapid evolution in informative

$\checkmark$ Leilani Asis

Imasis@ust.edu.ph

1 Professor, Section of Endocrinology and Metabolism, Department of Medicine

2 Program Director, Master in Public Health International, Faculty of Medicine and Surgery, University of Santo Tomas, Espana, Manila, Philippines communication technologies (ICTs), which revolutionized the online teaching and learning approach in medical education. [2,3,4]

This article will discuss the intricacies of DE on the influence of ICT in the pedagogical approach and outcome of teaching and learning and its impact on academic performance of students in the medical setting.

\section{Theories in Distance Education and How ICT Relates to Medical Education}

There are three (3) major theories that have shown significant influence in instructional design when one has to consider effective online teaching and learning.

Theory on Autonomy and Independent Study

The essence in DE is the independence of students. $[1,5]$ Independent study is individualizing teaching where learning is made convenient for students at their own environment and through students' activity. The learner takes responsibility for the pace of his or her own progress with the freedom to start and stop at any time.[5]

\section{Theory of Industrialization of Teaching}

In setting up a DE system, division of labor is an important prerequisite to obtain effective online teaching. $[1,6]$ Primary tasks are subdivided into subtasks. Major players are the school administration for 
policy making, instructional designers to retool blueprints from face-to-face scheme, the content experts who are the faculty staff of the curriculum, and the technology team to develop skills of faculty staff.[6]

\section{Theory of Interaction and Communication}

Teaching effectiveness in DE anchors on the impact of belonging and cooperation. $[1,7]$ The core of teaching is the interaction that will take place with the student and teacher. In such a relationship, emotional involvement contributes to the learning pleasure which eventually favors student motivation. Strong student motivation facilitates learning. [7]

\section{The Early Influence of ICT on Medical Education}

To appreciate the current scenario on how ICT invaded the world of medical education, let us reflect the basic background of medical teaching status in the traditional face-to-face setting. [2] Knowledge acquisition is primarily lecture-based to be assessed mostly in a multiple choice style of examinations, an approach of factual recall. As the students ascend in learning years, bulky books become innumerable, journals too many to count, and endless lectures to attend. The most challenging is the curriculum structure of departmental organization with identified block time which eventually gravitates into highly specialized branches of medicine. This adds up to the explosion of information that students have to bear that challenges their cognitive load heavily. [8]

The use of computer-assisted learning slowly became evident in the research work of medical students to access bibliographic literature through MEDLINE. [9] Word processing and e-mailing eased out reporting, sharing of information, and communication among teachers and classmates. The development of handheld devices like smartphones brought so much convenience to students in general. [10] Such devices could contain the previously bulky printed textbooks into eBooks. With the use of Wi-Fi there was easy access to updated journals, submission of assignments even in the wee hours of the day, recorded lectures, shared lectures, and was easy to have productive collaborative work among classmates anytime without regard to time zone and location.[10]

\section{elearning in Medical Education Through the Years}

Technologies are just one tool in the medical education toolbox. The task of instructional designers is to empower medical educators to utilize these new technologies effectively to transform learning into a more collaborative, personalized and empowering experience. The educational goals of using technology in medical education include facilitating basic knowledge acquisition, putting didactic knowledge into clinical events, improving decision-making, enhancement of perceptual variation, improving skill coordination, learning team training, and improving psychomotor skills. Technologies such as podcasts and videos with flipped classrooms, mobile devices with apps, video games, simulations (part-time trainers, integrated simulators, virtual reality), and wearable devices (google glass) are some of the techniques available to address the changing medical educational learning environment to mimic real life clinical scenarios.[1 1]

Research on the effect of flipped classrooms has shown a positive effect on student involvement, satisfaction and knowledge acquisition.[12,13] Simulation has been applied to imitate real patients, anatomic regions, or clinical tasks, and/or mirror the real-life circumstances in which medical services are rendered. Simulations can fulfill a number of educational goals namely, capture clinical variation, control the learning environment, individualized mastery of a specific clinical setting and an effective method for team training. Integrated simulators combine a mannequin (usually a whole body) with sophisticated computer controls that can be manipulated to provide various physiological parameter outputs.[3]

Virtual reality (VR) simulation refers to the recreation of environments or objects as a complex, computer-generated image. In VR simulations, the computer display simulates the physical world and user interactions are with the computer within that simulated (virtual) world. There are a number of VR programs used in medical education. One example, MIST VR (Minimally Invasive Surgery Trainer-Virtual Reality), has been specifically designed to provide trainees with a realistic and assessable environment for developing skills, particularly in the area of laparoscopy. $[3,14,15]$

Google Glass has been integrated into the medical curriculum in the USA. $[3,16,17]$ A teacher wears 
the gadget to project images (CTs, MRIs) into the field of vision as he operates to assist in cases where he can use additional clinical data to help guide the activity. The device has the unique ability to display information in a smartphone-like, hands-free format being able to communicate with the internet via voice commands and being able to securely broadcast and record patient care and student training activities.[16,17] Recording of these demonstrations add up to the resources for a repository of various clinical cases.

Most important in setting a DE system is the provision of a learning management system, a software system that enables the management and delivery of online and instructor-led training contents to learners. In such a setting, interaction through asynchronous activity like discussion forum and online debate or synchronous sessions like videoconferencing can be easily performed. Such a setting addresses the logistics concern for users and formal monitoring by the institution of academic activities of the faculty.

The transition of a medical school from a traditional face-to-face to online, distance, or electronic learning is beset with various constraints and challenges. The most challenging is to approximate the face-to-face teaching of clinical skills. The administration has the responsibility to provide, upgrade and maintain software and various technological resources. Deficit in technical skills of staff, balancing work with personal life, and poor communication were identified as one of the barriers that can inhibit medical educators' willingness to engage. [18] Likewise, lack of infrastructure and resources, cost and resistance from stakeholders were observed as stumbling blocks to sustain such online teaching programs. Understandably, solutions must be directed towards skill development of medical educators, institutional strategies, open communi- cation and engagement of staff on long-term planning.[18]

Digital divide is a situational gap between individuals, households, businesses and geographical areas at different socioeconomic levels with regard to both their opportunities to access ICTs and their use of the internet for a wide variety of activities. [19] Medical students may come from different socioeconomic backgrounds and connectivity has been shown to be poorest in low to middle income countries in Southeast Asia.[20] To offset such a predicament, instructional design of online activities must have a simple but appropriate media using print, audio and video, use of mix media, encourage resource-sharing and limit the range of technologies in a given circumstance.[2 1]

\section{CONCLUSION AND INSIGHT}

The application of DE in medical education has proven to be effective in addressing student satisfaction, engagement, motivation and excellent academic performance. How and what the students learn is the issue and technology is merely a tool. However, state-of-the-art resources are necessary to approximate face-to-face clinical skill teaching.

Collaborative planning with an instructional designer on which media is appropriate for a specific activity is vital in obtaining the desired outcome. The administration has the responsibility to empower faculty staff to develop the technological skill and provide, update and maintain softwares and other resources. Open communication must be exercised for the needs of both teachers and students.

Note: Prof. Leilani B. Mercado-Asis obtained her Masteral Degree in Distance Education, major in Instructional Design from the Athabasca University, Canada. 


\section{REFERENCES}

1. Simonson M, Zvacek SM, Smaldino S. Teaching and learning at a distance: Foundations of distance education. 5th ed. IAP; 2012.

2. Barnett GO. Information technology and medical education. Journal of the American Medical Informatics Association. 1995 Sep;2(5):285.

3. Bridge PD, Jackson M, Robinson L. The effectiveness of streaming video on medical student learning: a case study. Medical Education Online. 2009 Dec 1;14(1):4506.

4. Graafland M, Schraagen JM, Schijven MP. Systematic review of serious games for medical education and surgical skills training. British Journal of Surgery. 2012 Oct;99(10):1322-30.

5. Wedemeyer CA. Learning at the back door: Reflections on nontraditional learning in the lifespan. IAP; 2010 Jun 1.

6. Peters $O$. Distance teaching and industrial production: $A$ comparative interpretation in outline. In: Sewart D, Keegan, Holmberg B, editors. Distance education: International perspectives. New York: Routledge; 1988.

7. Holmberg B. The feasibility of a theory of teaching for distance education and a proposed theory (ZIFF Papiere 60). Hagen, West Germany: Fern Universität, Zentrales Institute fur Fernstudienforschung Arbeitsbereich. (ERIC Document Reproduction Service No. ED290013); 1985.

8. Sweller J. Cognitive load theory, learning difficulty, and instructional design. Learning and Instruction. 1994 Jan $1 ; 4(4): 295-312$.

9. US National Library of Medicine. MEDLINE®: Description of the database.

10. Moore R, Vitale D, Stawinoga N. The digital divide and educational equity: A look at students with very limited access to electronic devices at home. Insights in education and work. ACT, Inc. 2018 Aug.

11. Guze PA. Using technology to meet the challenges of medical education. Transactions of the American Clinical and Climatological Association. 2015;126:260.

12. Greenhalgh T. Computer assisted learning in undergraduate medical education. BM. 2001 Jan 6;322(7277):40-4.

13. Bridge PD, Jackson M, Robinson L. The effectiveness of streaming video on medical student learning: a case study. Medical Education Online. 2009 Dec 1;14(1):4506.
14. Wilson MS, Middlebrook A, Sutton C, Stone R, McCloy RF. MIST VR: a virtual reality trainer for laparoscopic surgery assesses performance. Ann R Coll Surg Engl. 1997 Nov;79(6):403-4.

15. McCloy R, Stone R. Virtual reality in surgery. BM. 2001 Oct 20;323(7318):912-5.

16. UC News, UCI School of Medicine first to integrate Google Glass into curriculum [Internet]. 2014 May 14.

17. Stratt N. Google opens its latest Google Glass AR headset for direct purchase [Internet]. 2020.

18. O'Doherty D, Dromey M, Lougheed J, Hannigan A, Last $\mathrm{J}$, McGrath D. Barriers and solutions to online learning in medical education-an integrative review. BMC Medical Education. $2018 \mathrm{Dec} ; 18(1): 130$.

19. Qi C, Chan C, Senkpiel H, Buschmaas J, Mendler L. Measuring the digital divide in the Asia Pacific region [Internet]. United Nations Economic and Social Commission for Asia and the Pacific. [cited 2020]. Available at: https://www. unescap.org/sites/default/files/S7.7 Measuring the Digital Divide in the Asia-Pacific Region, LSE.pdf

20. Khidhir S. ASEAN's poor mobile internet connectivity [Internet]. The ASEAN Post. 2018 [cited 2020 May29]. Available from: https://theaseanpost.com/article/ aseans-poor-mobile-internet-connectivity

21. Simonson M, Schlosser C. We need a plan: An instructional design approach for distance education courses. Distance Learning. 2004 Jul $1 ; 1(4): 29$.

cc) Open Access This article is licensed under a Creative Commons Attribution 4.0 International License, which permits use, sharing, adaptation, distribution and reproduction in any medium or format, as long as you give appropriate credit to the original author(s) and the source, provide a link to the Creative Commons license, and indicate if changes were made. The images or other third party material in this article are included in the article's Creative Commons license, unless indicated otherwise in a credit line to the material. If material is not included in the article's Creative Commons license and your intended use is not permitted by statutory regulation or exceeds the permitted use, you will need to obtain permission directly from the copyright holder. To view a copy of this license, visit http://creativecommons.org/licenses/by/4.0/. 